\title{
Atypical presentation of primary renal squamous cell cancer : a case report
}

\author{
Mrinal Pahwa ${ }^{1}$, Archna R. Pahwa ${ }^{2}$, Mohit Girotra ${ }^{3}$, Arun Chawla ${ }^{4}$

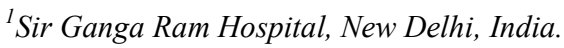 \\ ${ }^{2}$ Lady Hardinge Medical College, New Delhi, India. \\ ${ }^{3}$ University of Arkansas for Medical Sciences, Little Rock, Arkansas, USA. \\ ${ }^{4}$ Southside Kidney Specialist, Richmond, Virginia, USA.
}

Received November 2, 2013; Revised December 10, 2013; Accepted December 27, 2013; Published Online January 12, 2014

\section{Case Report}

\begin{abstract}
Renal squamous cell cancer is one of the rare primary urothelial tumors with only a handful of cases reported in literature. Because of high grade, advanced and late presentation, they herald a grave prognosis. They are frequently associated with calculus disease, smoking, phenacetin consumption and foci of squamous metaplasia due to chronic irritation. Nephroureterectomy is the treatment of choice for such tumors. We hereby present a case of 59 year old female who presented with squamous cell cancer of renal pelvis. The case presented here is different from what has already been reported in literature, as the patient had no antecedent risk factors for renal squamous cell carcinoma.
\end{abstract}

Keywords: Squamous cell cancer; Urothelial malignancy; Phenacetin; Smoking; Squamous metaplasia

\section{Introduction}

Renal squamous cell carcinoma (RSCC) is a rare cancer with a variable incidence of about $0.5-15 \%$ of all urothelial cancers. $^{1-4}$ The insidious onset of symptoms and lack of any pathognomonic sign leads to delay in diagnosis and treatment. These tumors are highly aggressive, high grade, and locally advanced or metastatic at the time of presentation. ${ }^{4}$ There are only isolated case reports and scant case series of such cases in English literature. ${ }^{2-5}$ The strongest association has been reported with renal calculus disease, in some series up to $100 \% .^{2,4}$ We hereby present a case of renal squamous cancer with left nonfunctioning kidney in which there were no antecedent risk factors.

\section{Case Report}

59-year-old female presented with complaints of left side abdominal pain which was dull aching and non-radiating. There was no past history of renal stone disease. On evaluation with contrast enhanced computed tomography of Kid-

Corresponding author: Mrinal Pahwa, DNB, MS; 78-c, Mianwali colony, Gurgaon-122001, India.

Email: drmrinalpahwa@gmail.com

Cite this article as:

Pahwa M, Pahwa AR, Girotra M, Chawla A. Atypical presentation of primary renal squamous cell cancer: a case report. Int J Cancer Ther Oncol 2014; 2(1):02015.

DOI: $10.14319 /$ ijcto.0201.5 ney Ureter Bladder (CECT KUB), patient was found to have necrotic mass in region of left kidney causing left side hydronephrosis and hilar mass inseparable from renal pelvis (Figure 1). Patient was subjected to laparoscopic nephroureterectomy. Intraoperatively, a hard mass of $8 \times 8$ $\mathrm{cm}$ was found in left renal pelvis, confined within gerotas fascia.

Microscopic examination revealed malignant tumor comprising of squamoid cells with a lot of keratinisation, infiltrating extensively around pelviureteric area and deeply into renal parenchyma (Figure 2). Two of the seven lymph nodes were found to be infiltrated by tumor in hilar region. Patient had an uneventful postoperative recovery. Patient was not given any adjuvant chemotherapy or radiotherapy. Patient was kept on regular follow-up and has been doing well for the past 9 months with no evidence of any recurrence or metastasis.

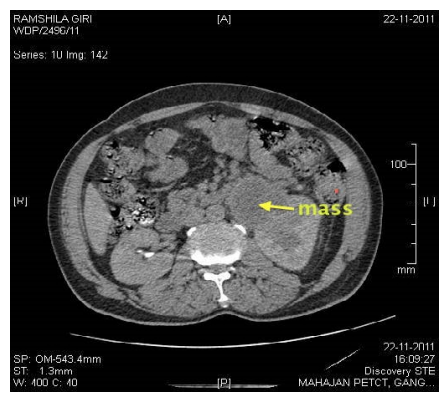

FIG. 1: CT scan showing large heterogeneous hilar mass in left kidney with left hydronephrosis. 


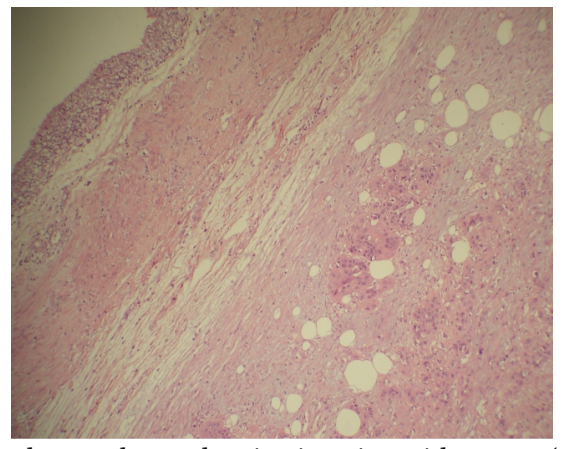

FIG. 2: Renal parenchyma showing invasion with tumor. (400x)

\section{Discussion}

Squamous cell carcinoma of the urinary tract is more frequently reported in urinary bladder and male urethra and rarely encountered in renal pelvis. ${ }^{2-5}$ The mean age of presentation is $\mathbf{5 6}$ years, and recent case series have shown that there is equal incidence in males and females. The involvement is unilateral, equally common on the right and left sides. Tumor may present as loin pain, hematuria, abdominal lump or with anorexia and weight loss in advanced cases.1,2,4 The etiological factors which play in the genesis of this rare malignancy are strongly associated with phenacetin consumption, chronic renal calculi, pyelonephritis and squamous metaplasia. History of previous surgery for renal stone or staghorn calculi in patients of RSCC has been reported in 12.3 - 100\% of cases. ${ }^{2,4}$ There have been very few instances when squamous cell cancer of renal pelvis has been observed in the absence of renal calculi or other risk factors. ${ }^{6,7}$ Significantly, due to nonspecific and insidious presenting symptoms, lack of specific radiological features, and rarity of this tumor, most cases of RSCC are undiagnosed preoperatively and diagnosis is only made by histopathological examination of the operated nephrectomy specimen..$^{2,3,8,9}$

The tumor may be detected by conventional radiological imaging like intravenous pyelogram where one may observe nonspecific findings like filling defects, obstructing lesions, non-functioning renal unit etc. CT may be more sensitive and specific in picking up such findings but may not be routinely done in all patients with stone disease as both tumor and stone may present with overlapping symptoms. ${ }^{3}$ Imbriaco et al. reported renal SCC within a horseshoe kidney associated with renal stones with non-specific CT and MRI findings. ${ }^{10}$ Lee et al. in their study classified these tumors into two groups, according to localization of the tumors as central and peripheral, with centrally located tumors having significantly lower survival rates. ${ }^{3}$

Insidious onset of the disease, lack of any pathognomonic sign or symptom and nonspecific findings on imaging leads to delay in diagnosis. Hence, most of the patients present with advanced disease, accounting for poor prognosis. The outcome of RSCC patients is poor with median survival of only $5-7$ months after surgery and a 5 year survival of less than $10 \% .^{1,2,4,5,7,11}$

The current primary treatment of renal squamous cell carcinoma is nephroureterectomy. Nephrectomy is necessary even in the face of metastatic disease; to establish a histological diagnosis, for control of symptoms such as pain, fever and hematuria or to eliminate the source of infection before systemic chemotherapy can be instituted. Cisplatin-based adjuvant chemotherapy and radiotherapy are usually given due to the advanced stage and poor prognosis in most patients but have shown no survival benefit, highlighting the need for early diagnosis. ${ }^{1,4}$ The follow up of these patients is not standardized but includes physical examination, chest X-Ray and liver function tests. Check cystoscopy is rarely performed in these patients, as it's rare for renal squamous cancer to present with bladder tumor in follow-up.

The case presented here is different from what has already been reported in literature, as the patient had no antecedent risk factors for renal squamous cell carcinoma. The patient underwent radical nephrectomy without any chemotherapy or radiotherapy, with disease free survival of 9 months till now.

\section{Conflict of interest}

The authors declare that they have no conflicts of interest. The authors alone are responsible for the content and writing of this case report.

\section{References}

1. Blacher EJ, Johnson DE, Abdul-Karim FW, Ayala AG. Squamous cell carcinoma of renal pelvis. Urology 1985; 25:124-6.

2. Li MK, Cheung WL. Squamous cell carcinoma of the renal pelvis. J Urol 1987; 138:269-71.

3. Lee TY, Ko SF, Wan YL, Cheng YF, et al. Renal squamous cell carcinoma: CT findings and clinical significance. Abdom Imaging 1998; 23:203-8.

4. Holmang S, Lele SM, Johansson SL. Squamous cell carcinoma of the renal pelvis and ureter: incidence, symptoms, treatment and outcome. J Urol 2007; 178:51-6.

5. Karabulut A, Emir L, Gonultas NI et al. Squamous cell carcinoma located in the renal caliceal system: A case report and review of the literature. Turkish J of Cancer 2002; 32:20-4.

6. Bandyopadhyay R, Biswas S, Nag D, Ghosh AK. Squamous cell carcinoma of the renal pelvis presenting as hydronephrosis. J Cancer Res Ther 2010; 6:537-9.

7. Talwar N, Dargan P, Arora MP, Sharma A, Sen AK. Primary squamous cell carcinoma of the renal pelvis 
masquerading as pyonephrosis: a case report. Indian $J$ Pathol Microbiol 2006; 49:418-20.

8. Jain A, Mittal D, Jindal A, Solanki R, Khatri S, Parikh A, et al. Incidentally detected squamous cell carcinoma of renal pelvis in patients with staghorn calculi: Case series with review of the literature. ISRN Oncol 2011; 2011:620574.

9. Berz D, Rizack T, Weitzen S, Mega A, Renzulli J, Colvin G. Survival of patients with squamous cell malignancies of the upper urinary tract. Clin Med Insights Oncol 2012; 6:11-8.
10. Imbriaco M, Iodice D, Erra P, Terlizzi A, Di Carlo R, Di Vito C, et al. Squamous cell carcinoma within a horseshoe kidney with associated renal stones detected by computed tomography and magnetic resonance imaging. Urology 2011; 78:54-5.

11. Bhaijee F. Squamous cell carcinoma of the renal pelvis. Ann Diagn Pathol. 2012; 16:124-7. 